\title{
O DIREITO FUNDAMENTAL DE PROTEÇÃO AO CONSUMIDOR EM TEMPOS DE GLOBALIZAÇÃO E O FENÔMENO DO SUPERENDIVIDAMENTO
}

\author{
Mario Furlaneto Neto ${ }^{1}$ \\ Gabriela Cristina Bezen ${ }^{2}$
}

\begin{abstract}
Resumo
A presente pesquisa tem por objetivo analisar e verificar o fenômeno da globalização como uma forma de facilitar a comunicação entre nações e a finalidade de fomentar as práticas comerciais, destacando o seu desenvolvimento que corroborou para um novo contexto social de produção, a qual faz emergir uma nova sociedade denominada de sociedade de consumo. Por meio de revisão bibliográfica e legislativa, destaca-se a evolução das relações de consumo e verifica-se que, ainda que a proteção do consumidor tenha sido positivada no ordenamento jurídico brasileiro pela Constituição Federal/88 como um direito fundamental, regulamentou e tenha sido promulgado o Código de Defesa do Consumidor em 1990, o fenômeno do superendividamento como uma consequência da globalização continua sem regulamentação. A pesquisa estaca a importância do consumo na inclusão ou exclusão do cidadão na sociedade atual de consumo e o seu reflexo no princípio da dignidade, assim como, necessário, também, verificar as consequências sociais e jurídicas destes fenômenos numa sociedade e examinar as causas do superendividamento e o desafio enfrentado para que seja efetiva a proteção do consumidor ante a lacuna da norma consumerista, ainda que hoje tramite no Senado Federal, projeto de lei que visa disciplinar o crédito e prevenir o superendividamento.
\end{abstract}

Palavras-chave: Consumo; Direito Fundamental; Globalização; Proteção do Consumidor; Superendividamento.

\section{INTRODUÇÃO}

A globalização como forma de integração entre nações ou "intensificação das relações sociais em escala mundial" (GIDDENS, 1991, p. 76) traz como característica a abertura de novos mercados e, fomentada pela rede mundial de computadores, a possibilidade de comunicação instantânea, fazendo emergir junto com os avanços tecnológicos a questão da standartização - massificação - dos produtos e serviços.

Tem-se que este fenômeno, potencializado pela Internet, corroborou para o surgimento de um novo modelo de sociedade: a sociedade de consumo. Possibilitou, também, a expansão e o aumento progressivo da oferta de variados produtos e serviços, que constituem uma das ferramentas para o desenvolvimento econômico.

\footnotetext{
${ }^{1}$ Professor do Mestrado em Direito do UNIVEM - Centro Universitário Eurípides de Marília. Coordenador do NEPI - Núcleo de Estudos e Pesquisas em Direito e Internet. E-mail: mariofur@univem.edu.br

${ }^{2}$ Mestranda em Direito pelo UNIVEM - Centro Universitário Eurípides de Marília. Professora na Comarca de Sinop-MT. E-mail: gabibezen@hotmail.com.
} 
Pode-se considerar que o processo histórico da globalização contribuiu para fortalecer o consumismo moderno. O consumo passa a influenciar o comportamento do indivíduo e seu modo de vida, despertando desejos de novos produtos e serviços.

O surgimento de práticas comerciais agressivas e métodos de publicidade atingem diariamente toda uma coletividade de indivíduos, agravando a vulnerabilidade destes enquanto consumidores.

A globalização e o novo modelo de sociedade de consumo foram oportunos para o capitalismo gerar formas propícias de trabalho com minimização de custo global e maximização de atendimento da demanda, todavia, sem elevar a renda dos trabalhadores, o que veio a refletir diretamente na qualidade de vida do ser humano.

O superendividamento é um problema social na medida em que o crédito fácil e desmedido é cada vez mais facilitado, acarretando como consequência a exclusão social, assim como um problema econômico diante da impossibilidade de o indivíduo cumprir com suas obrigações, levando-o a insolvência civil. Tem-se, ainda, um problema jurídico perante a falta de regulamentação.

O princípio fundamental de proteção ao consumidor foi positivado no ordenamento jurídico brasileiro pela Constituição Federal de 1988 e surge como uma forma de atender a nova realidade, numa tentativa de harmonizar e equilibrar as relações de consumo e, em decorrência dessa norma imperativa, em 1990, foi promulgado o Código de Defesa do Consumidor.

É preciso ponderar que o Código de Defesa do Consumidor, apesar de um marco normativo, foi organizado num período em que não existiam as facilidades de acesso a produtos e serviços, bem como a facilidade de acesso ao crédito, sendo omisso quanto a questões dessa nova sociedade de consumo ou sociedade moderna e pós-moderna.

Nesse contexto, tramita no Senado Federal o projeto de lei no 283, de 2012, que tem por finalidade a inclusão de normas de cunho principiológicas concernentes à concessão de crédito e meios de prevenir o superendividamento.

Por este motivo, é urgente e necessário o tratamento efetivo desse fenômeno por meio de uma norma específica que traga segurança jurídica e atenue a situação de vulnerabilidade do consumidor. A falta dessa regulamentação é uma afronta ao direito fundamental de proteção do consumidor e implica na violação do princípio da dignidade da pessoa humana ao privar o indivíduo do mínimo para uma vida digna.

Nesse sentido, por meio de revisão bibliográfica e legislativa, objetiva-se verificar e compreender a relação que existe entre a globalização, o consumo, a proteção do consumidor como direito fundamental e o superendividamento, levando-se em consideração as características de cada um desses fenômenos e as consequências ocasionadas à sociedade. 
Procura-se confirmar a hipótese de que a ausência de tutela contra o superendividamento do consumidor viola a Constituição Federal que exige a atuação do Estado para a efetiva proteção do consumidor, e, ainda, a violação do princípio da dignidade da pessoa humana, diante as consequências desse fenômeno, privando o consumidor do mínimo para a sua subsistência.

Para tanto, antes de analisar o instituto do superendividamento, necessário se torna pontuar aspectos pertinentes à globalização e a sociedade de consumo, o que se fará a seguir.

\section{O FENÔMENO DA GLOBALIZAÇÃO E A SOCIEDADE DE CONSUMO}

A Revolução Industrial é considerada um marco na forma de produção. Anteriormente a esse movimento, a produção se dava de forma artesanal, manual, restrita ao cerne familiar ou a um pequeno número de pessoas. Posteriormente, a produção passou a ser em grande escala.

Lima e Ayala (2012, p. 173) comentam que as transformações oriundas da Revolução Industrial marcaram o início da fase Moderna, que apresentou um novo modelo econômico: o capitalismo. Assim:

Esse fenômeno, o da Revolução Industrial, que ocorreu na segunda metade do século XVIII, representou um marco histórico para a humanidade, dando o início à fase Moderna. O novo modelo inaugurado pôs fim ao sistema mercantilista que predominava até então para dar origem a um novo modelo econômico, o Capitalismo. Dentre as diversas transformações ocorridas proporcionadas pela Revolução Industrial é importante destacar o aumento populacional, o crescimento das concentrações urbanas e, especialmente, o avanço tecnológico que, somado ao desenvolvimento dos métodos dominantes de produção, intensificou a apropriação dos recursos ambientais, proporcionando o desenvolvimento industrial.

Giddens (1991, p. 67) ressalta que o capitalismo e o industrialismo são "dimensões diferentes envolvidas nas instituições da modernidade". Para o autor, o capitalismo é marcado por uma relação entre classes: o proprietário privado do capital e os assalariados. Aquele "depende da produção para mercados competitivos", em que o preço é ponto comum para "investigadores, produtores e consumidores". Por sua vez, pontua que o industrialismo está fortemente ligado à mecanização no processo de produção de bens.

Inegável que a sociedade capitalista e o industrialismo ganharam maior impulsão com os avanços tecnológicos, com a informática e os meios de comunicação.

O fenômeno da globalização não é atual e apresenta diversas definições, estando originalmente relacionado com as grandes navegações e tem como função estabelecer uma integração entre países, realizar transações financeiras, comerciais e diversificar as culturas.

Pode-se dizer que dentre algumas vertentes da globalização, observa-se a facilitação da comunicação entre nações com a finalidade de fomentar práticas mercantis, bem como trocas de informações e conhecimentos.

Silveira Neto (2002, p. 56) explica que "a globalização econômica deve ser entendida como um processo 
de integração mundial dos fatores de produção que levou a uma ampliação do comércio internacional, assentado numa estrutura de produção descentralizada”.

Nesse diapasão, a globalização se revela como uma nova fase do capitalismo mundial. É marcada por mudanças nas instituições políticas e econômicas que interferiu nos hábitos culturais de todas as nações.

Carvalho $(2015$, p. 9) descreve que "os processos da globalização consistem em um fenômeno múltiplo com dimensões econômicas, sociais, políticas e culturais, interligadas de modo complexo, em escala local e global".

Pode-se dizer que a globalização incide na elevação dos Estados, das sociedades e dos governos mundiais, e deriva do capitalismo desorganizado. Desta maneira, o progresso do desenvolvimento trouxe o contexto social da produção, fazendo surgir a sociedade de consumo, que origina transformações na vida social moderna, modificando a vida das pessoas.

O consumo é necessário para a sobrevivência dos indivíduos, bem como faz parte da natureza humana, no entanto, a consagração do capitalismo fomenta o consumo e, por conseguinte, aumenta as necessidades do indivíduo.

Retondar (2007, p. 138) explica que:

A sociedade de consumo caracteriza-se, antes de tudo, pelo desejo socialmente expandido da aquisição "do supérfluo", do excedente, do luxo. Do mesmo modo, se estrutura pela marca da insaciabilidade, da constante insatisfação, onde uma necessidade preliminarmente satisfeita gera quase automaticamente outra necessidade, num ciclo que não se esgota, num continuum onde o final do ato consumista é o próprio desejo de consumo.

A sociedade de consumo impulsiona o indivíduo a satisfazer suas necessidades primárias e, posteriormente, buscar a satisfação de outras e outras necessidades, e, assim, sucessivamente, de acordo com as suas prioridades.

A importância da relação de consumo está sob enfoque não somente no contexto da relação jurídica, pois antes de produzir efeito na ordem jurídica e vir a ser disciplinado pelo Direito, o consumo possui cunho nas relações sociais.

O consumo labora como um fator de inclusão social do indivíduo para com a sociedade, conquanto for consumidor nos dias atuais significa afirmar que hoje se é globalizado, ou seja, que está diretamente conectado ao mundo e ao que ele tem a oferecer.

As formas de marketing, os meios de comunicação, a Internet, como forma de comprimir o tempo e o espaço, fomentam o consumo e aumentam a necessidade de estar inserido na nova sociedade de consumo.

Retondar (2007, p. 141) expõe que:

Em termos propriamente sociológicos, essa mudança não é apenas uma mudança quantitativa que se dá no campo do consumo por intermédio da maior disponibilidade e variedade de bens. Ao contrário, reflete uma mudança na própria lógica social do consumo, que passa de uma relação de massificação do consumidor para uma hipertrofia de sua individualidade. 
A mudança das relações de consumo não implica apenas no caráter quantitativo devido à massificação da produção, onde se tem acesso a diversos e variados produtos em curto período de tempo, mas, também, de uma mudança social marcada pelo princípio da individualização.

No campo social, ocorre a intensificação da ideologia e da cultura em direção ao desenvolvimento de modos de comportamento individuais, de maneira que, o consumo passa a ser uma das ferramentas do capitalismo.

O mercado de consumo, em face da globalização, apresenta como molde de consumo a busca incessante por lucros por parte dos fornecedores que tentam, a todo o momento, despertar desejos e induzir o consumidor, para que este venha a consumir novos produtos e serviços, formando um processo cíclico.

Nota-se que a globalização está diretamente relacionada ao consumo de massa, em que o indivíduo está inserido na sociedade para desempenhar sua identidade que foi construída pelo ato de consumir.

Ainda, sob este enfoque, Retondar (2007, p. 144 e 145) esclarece que:

Se pensarmos a esfera contemporânea do consumo como um sistema de comunicação social, aonde os diversos produtos e bens são constantemente associados a distintos universos significativos e, ainda, que tal associação se dá de maneira cada vez mais flexível, o ato de consumo transforma-se, neste caso, num ato de adesão simbólica em que a escolha do objeto se torna uma escolha estratégica, por meio da qual o consumidor vai continuamente definindo e redefinindo sua identidade.

Nesse sentido, o fenômeno da globalização fomentando o consumo desenfreado, desencadeando a formação de identidade do indivíduo, evidencia o enfoque do estudo científico da relação de consumo e do consumismo no caráter social, sendo nos dias atuais, o consumo um fator de inclusão social do homem com os demais, de maneira que, ser consumista é ser globalizado. A contrapartida é a preocupação com o fenômeno da exclusão social.

No contexto jurídico, a globalização emana o fortalecimento dos fornecedores devido à ampliação da produção e oferta global e que faz elevar demasiadamente a vulnerabilidade do consumidor e aumenta a dificuldade de protegê-lo. Assim, a globalização afeta diretamente o mercado de consumo e, principalmente, no papel do Estado no dever de Defesa do Consumidor.

Todo esse contexto da nova sociedade de consumo faz gerar a necessidade de fortalecer a atuação estatal na proteção da sociedade e indivíduo, em especial, nas relações de consumo com a finalidade de garantir a dignidade imposta pela Constituição Federal.

\section{FUNDAMENTOS CONSTITUCIONAIS DO DIREITO DO CONSUMIDOR}

Os direitos fundamentais configuram-se como o mínimo necessário para existência digna das pessoas, tendo o princípio da dignidade da pessoa humana como um de seus fundamentos, e representa a conquista de 
gerações com a evolução do Estado de Direito. Assim, tais direitos vieram a limitar a atuação estatal, ao mesmo tempo em que o obriga a agir positivamente para garantir tais direitos existentes no ordenamento jurídico.

De acordo com Mendes e Branco (2014, p. 136):

Os direitos fundamentais assumem posição de definitivo realce na sociedade quando se inverte a tradicional relação entre Estado e indivíduo e se reconhece que o indivíduo tem primeiro direitos, e, depois, deveres perante o Estado, e que os direitos que o Estado tem em relação ao indivíduo se ordenam ao objetivo de melhor cuidar das necessidades dos cidadãos.

Desta maneira, tem-se que os indivíduos possuem direitos frente ao Estado, cabendo a este atuar de forma a garantir estes numa perspectiva de melhor cuidar as necessidades de seus cidadãos e que somente após a garantia destes direitos possuem deveres.

Segundo entendimento de Canotilho (2000, p. 393), "os direitos fundamentais seriam os direitos objetivamente vigentes numa ordem jurídica concreta".

Destarte, entender-se-á que os direitos fundamentais vieram assegurar aos indivíduos condições necessárias para o convívio em sociedade, assim, tornando-se necessários e indispensáveis para assegurar uma existência livre, digna e igualitária.

Nessa toada, a Constituição Federal de 1988 consagrou o princípio da dignidade da pessoa humana como um dos fundamentos do Estado Democrático de Direito, previsto no art. 1º, inciso III. Tal princípio constitui o alicerce e embasamento de todo o ordenamento jurídico brasileiro, fundado na ideia de que a pessoa humana é a razão de ser do Direito e do Estado.

Neste sentindo, "a dignidade da pessoa humana é preceito basilar que impõe o reconhecimento de que o valor do indivíduo, enquanto ser humano, prevalece sobre todos os demais" (MOTTA; BARCHET, 2008, p. 84, $85)$.

Negar a expectativa de um melhor bem-estar de vida, expondo o indivíduo a riscos sociais, comprometendo suas condições, sejam materiais e/ou afetivas, ao mínimo da condição de uma vida digna, é um desrespeito ao fundamento da dignidade da pessoa humana.

A dignidade da pessoa humana é o valor supremo de uma nação, de um Estado Democrático de Direito, é o princípio de normatização de todas as demais normas; é assim que a Constituição Federal de 1988 declara este princípio, de forma que o Estado deve condicionar o mínimo necessário para uma vida digna.

Assim, levando em conta que a relação de consumo é uma relação de desiguais, tendo o consumidor em situação de vulnerabilidade, e o fornecedor, enquanto detentor do monopólio dos meios de produção, indispensável pontuar que o Direito do Consumidor fosse elevado a um direito fundamental.

Diante essa situação de vulnerabilidade do consumidor e as premissas de defesa do consumidor surgindo em todo o mundo, a Constituição Federal de 1988 positivou no ordenamento jurídico brasileiro a 
defesa do consumidor como um princípio fundamental do estado democrático de direito, ao prescrever a tutela enquanto dever do Estado.

Portanto, o art. 5\%, inciso XXXII, da CF incorporou uma tendência mundial de influência do direito público sobre o direito privado, chamado pela Doutrina de 'constitucionalização do Direito Civil' ou de 'Direito Civil Constitucional'. Nesse sentido, o legislador constituinte, ao elevar a defesa do consumidor como direito fundamental do cidadão, estipulou o dever de o Estado promover a proteção do mesmo.

Marques (2010, p. 33-34 apudBOLZAN, 2015, p. 38) considera:

A Constituição Federal de 1988 como o centro irradiador e o marco de reconstrução de um direito privado brasileiro mais social e preocupado com os vulneráveis de nossa sociedade, um direito privado solidário. Em outras palavras, a Constituição seria a garantia (de existência e de proibição de retrocesso) e o limite (limite-guia e limite-função) de um direito privado construído sob seu sistema de valores e incluindo a defesa do consumidor como princípio geral.

Assim, compete ao Estado a responsabilidade de fomentar e facilitar a defesa do consumidor como vulnerável da relação de consumo diante o amparo constitucional do direito do consumidor como uma ordem imperativa.

A CF, também, introduziu a figura do consumidor como agente econômico e social, conforme art. 170, V, consagrando um sistema capitalista instituído na livre iniciativa e na valorização do trabalho humano e que tem por objetivo garantir uma existência digna aos cidadãos.

Assim esse princípio, como norma de ordem pública e social, possui como finalidade o intuito de limitar a autonomia privada da vontade e coibir abusos por parte dos agentes econômicos, ou seja, se deve ao fato de um lado da relação ter o hipossuficiente que está em desvantagem com a outra parte, dependendo de uma proteção legal.

Observado a necessidade de uma norma que efetivasse a defesa do consumidor como princípio constitucional, em 1990 foi promulgada a Lei 8.078/1990, denominada de Código de Defesa do Consumidor (CDC), que consiste numa norma principiológica e visa equilibrar e harmonizar a relação de consumo entre consumidor e fornecedor no ordenamento jurídico brasileiro.

Desta forma, a CF, ao prever a defesa do consumidor como direito fundamental, por conseguinte, garante que os direitos previstos no $\mathrm{CDC}$ ou em qualquer outra fonte do direito que trate sobre a relação de consumo, ganhem status de direitos fundamentais, e que devem ser protegidos rigorosamente pelo ordenamento jurídico brasileiro. 


\section{O SUPERENDIVIDAMENTO DO CONSUMIDOR COMO CONSEQUENCIA DA GLOBALIZAÇÃO}

Como já alinhavado, na nova sociedade de consumo observa-se o aumento da produção, a padronização de produtos, a massificação e a agressividade da publicidade e, ainda, a prevalência das contratações standartizadas através dos contratos de adesão, despertando nos indivíduos a ideia de satisfação ligada ao consumo, criando o ambiente propício para a condição do superendividamento do indivíduo como consumidor.

O superendividamento surge como consequência da atual sociedade de consumo, originária da globalização e do capitalismo, e se dá pelo consumo desenfreado na busca da satisfação de desejos e na intenção de conquistar um melhor bem estar e até mesmo status pessoal e social.

O indivíduo com o objetivo de assumir uma posição de vida melhor, conforto, status social e pessoal, passa a consumir por consumir, não percebendo que a prática desse ato de consumo foge ao seu controle, fazendo com que não possa adimplir com suas obrigações, vindo a incidir no estado de insolvência de suas dívidas.

$\mathrm{O}$ art. $54, \$ 1^{\circ}$ do projeto de lei $283 / 2012$, conceitua o superendividamento como sendo "a impossibilidade manifesta do consumidor, pessoa natural, de boa-fé, de pagar o conjunto de suas dívidas de consumo, exigíveis e vincendas, que comprometa seu mínimo existencial".

Pode-se definir o fenômeno do superendividamento pela caracterização da insuficiência de recursos econômicos da pessoa física para o cumprimento de seus encargos financeiros, apresentando como resultado o aumento de suas dívidas diante de sua renda.

Claudia Lima Marques define o fenômeno como:

[...] impossibilidade global do devedor pessoa física, consumidor, leigo e de boa-fé, de pagar todas as suas dívidas atuais e futuras de consumo (excluídas as dívidas com Fisco, oriunda de delitos e de alimentos) em um tempo razoável com sua capacidade atual de rendas e patrimônio. (MARQUES, 2006, p. 256, apudBOLADE, 2012, p. 184).

Nesse sentido, o superendividamento atinge o indivíduo consumidor de boa-fé, ou seja, aquele que tinha a intenção inicial de adimplir com suas dívidas e deixou de fazê-lo por razão diversa a sua vontade. (BOLADE, 2012, p. 184).

Fabiana A. de Almeida Oliveira Pellegrino, explica que o fenômeno do superendividamento é intrínseco a própria sociedade standartizada e que resulta da expansão e concessão irresponsável do crédito; tem-se o surgimento do superendividamento, assim:

Como fenômeno social, jurídico e econômico, inerente à sociedade de massa, resultante de uma expansão e concessão irresponsável de crédito, capaz de gerar a impossibilidade do consumidor, pessoa física, de boa-fé, de pagar o conjunto de suas dívidas de consumo, vencidas ou a vencer, sem prejuízo grave do sustento próprio ou de sua família. (PELLEGRINO, 2014, p. 173).

Nesse sentido, tem-se este fenômeno como a situação do consumidor, de boa-fé, que contraí 
determinadas quantidades de obrigações financeiras e que não consegue cumprir com os rendimentos que percebe.

Ainda, Marques (2010, p. 408) conceitua o superendividamento como "uma crise de solvência e de liquidez do consumidor (com reflexos em todo o seu grupo familiar), crise que facilmente resulta em sua exclusão total do mercado de consumo, comparável a uma nova espécie de 'morte civil'”.

Notadamente, o superendividamento pode ser definido como a impossibilidade de um indivíduo, pessoa física, devedor e de boa-fé, de efetuar o pagamento de suas dívidas atuais e futuras, ou seja, o consumidor, em decorrência de inúmeras obrigações, em um determinado momento, não é capaz de adimplir suas dívidas.

Destaca-se que o conceito de endividamento acima dos limites possíveis decorre da impossibilidade do indivíduo de cumprir com o pagamento de suas dívidas oriundas de necessidades básicas.

Para tanto, não se deve concluir que o indivíduo é superendividado pelo simples atraso de um pagamento, como um atraso temporário, mas, num atraso duradouro, onde na união de inúmeras obrigações faz com que este indivíduo, em um determinado momento, não seja capaz de adimplir suas dívidas.

O superendividamento pode ser caracterizado pela má administração do orçamento familiar, abuso de crédito, desemprego, acidentes, doenças, divórcio, dentre outros fatores que podem levar o indivíduo a não poder cumprir com o adimplemento de suas dívidas.

Marques (2010, p. 408) aponta alguns fatores que podem corroborar para que o indivíduo se torne insolvente, como:

A massificação do acesso ao crédito; a forte privatização dos serviços essenciais e públicos, agora acessíveis a todos, com qualquer orçamento; as duras regras do mercado em que o nome nos bancos de dados negativos pode significar a impossibilidade de conseguir novo emprego; a nova publicidade agressiva sobre crédito popular nas ruas; a nova força dos meios de comunicação de massa e, finalmente, a tendência de abuso impensado do crédito facilitado e ilimitado no tempo e nos valores, inclusive com descontos em folha de trabalhadores ativos e aposentados, pode levar o consumidor e sua família facilmente a um estado de "superendividamento".

A despeito disso, o superendividamento, na maioria dos casos, não decorre de uma única causa, isso, pois, o indivíduo consumidor faz frente a um conjunto de obrigações que derivam de aquisições para satisfação de primeira necessidade, como móveis, alimentação, carro e outros.

Ainda, poder-se-á afirmar que o superendividamento, também, pode originar-se de causas não econômicas como a falta de políticas públicas para a regulamentação desse fenômeno, a falta de informação e educação para o consumo consciente, bem como, ainda, acidentes e/ou enfermidades, rupturas familiares e outras.

Independentemente de quais sejam as causas que ocasionam o superendividamento, a impossibilidade do indivíduo de adimplir com suas obrigações apresenta como consequência a situação de sua exclusão do meio 
social, podendo, ainda, levá-lo a viver sobre padrões abaixo do mínimo de dignidade.

Dentre as causas do superendividamento, uma das que mais se destacam é a oferta de crédito, por ser um dos meios mais comuns da acumulação de bens. Assim, explica Fossa (2012, p.5): "o carro do ano, dinheiro fácil e rápido, iPad, celulares de última geração, televisores 3D, muitas famílias desfrutam destes bens colocados no mercado e adquiridos mediante diversas oferta de crédito".

A vulgarização de ofertas por mensagens diárias de parcelamento facilitado, menor risco, baixas taxas de juros e outras que levam o indivíduo, consumidor, a aderi-las e que ao final de cada mês, seu salário acaba servindo apenas para quitar essas dívidas.

O fenômeno do superendividamento divide-se em dois tipos, o passivo e o ativo.

Poder-se-á entender o superendividamento ativo quando da identificação de uma acumulação imponderada de dívidas contraídas pelo indivíduo consumidor. Desta maneira, encontram-se abarcadas nesse tipo do fenômeno as situações em que o consumidor corroborou para o estado de insolvência.

Geisianne Aparecida Bolade (2012, p. 185) explica que o superendividamento ativo "é causado pela prática de um ato pelo consumidor", ou seja, é aquele em que o indivíduo consumidor contribui para a situação desse fenômeno.

Esta tipologia decorre daquela em que "o consumidor contribuiu para se colocar em estado de insolvabilidade, contraindo dívidas de forma exagerada e sem planejamento pessoal, buscando manter um padrão de dignidade que ele mesmo se impõe" (PELLEGRINO, 2014, p. 177).

Ademais, o superendividamento ativo subdivide-se em consciente e inconsciente.

Poder-se-á entender como superendividamento ativo consciente aquele em que o indivíduo consumidor, de má-fé, contrai dívidas, ciente de que não poderá cumpri-las.

Nesta forma de superendividamento ativo, não se faz necessária o apoio do Estado para o indivíduo consumidor vir a se recuperar, pois, não atende o requisito para o enquadramento do fenômeno do superendividamento, qual seja, a boa-fé.

Assim, tem-se que:

é aquele proveniente do comportamento econômico do consumidor no sentido de contrair dívidas, ciente da probabilidade de não honrá-las e de que o credor não encontrará meios para o recebimento do crédito. [...]; Nessas situações, aferida a ausência de boa-fé do consumidor, o devedor não receberá respaldo estatal para se recuperar, até porque o próprio conceito de superendividamento insere a boa-fé como pressuposto para sua caracterização (PELLEGRINO, 2014, p. 177)

O superendividamento inconsciente é aquele em que o indivíduo consumidor contrai dívidas, de boa-fé, convicto de que poderá salda-las.

Esta tipologia enquadra-se no amparo, pois o consumidor que, não sendo acometido por nenhum acontecimento superveniente, superendividou-se por impulso, por inconsequência até mesmo em decorrência 
dos diversos encantos da sociedade de consumo, mas de boa-fé.

Geisianne Aparecida Bolade (2012, p. 185), esclarece que

o consumidor que está superendividado em decorrência da falta de cautela em seus gastos, ou seja, não há o elemento da má-fé, pois, quando assume suas dívidas temo ânimo de quitálas, mas por falta de controle sobre seus gastos e rendimentos acaba assumindo mais compromissos financeiros que seus rendimentos são capazes de suportar.

Nesta forma, o indivíduo consumidor superestima a sua renda por incapacidade de administrar o seu orçamento ou por ceder aos encantos do consumo e da própria publicidade por meio do marketing agressivo, na busca de um padrão de vida mais digno.

Já, na tipologia do superendividamento passivo, o indivíduo consumidor enquadra-se nesse fenômeno por motivos alheios a sua vontade, ou seja, o consumidor não contribui ativamente para essa situação.

O superendividamento passivo ocorre quando o consumidor não contribui ativamente para o aparecimento dessa crise, de forma que a impossibilidade do consumidor adimplir suas obrigações surge em razão de algum acidente da vida: como desemprego, divórcio, nascimento de filho ou doença. (FERNANDES, 2015, p. 57).

Pellegrino (2014, p. 178-179) elucida que "por áleas da vida contemporânea, que desestabilizam a situação financeira do agregado familiar, inviabilizando o cumprimento dos compromissos firmados em momento de segurança financeira".

Desta maneira, poder-se-á afirmar que nessa tipologia, o indivíduo consumidor, enquadra-se nessa situação decorrente de fatores externos, ocorrem por acidentes da vida sendo suas consequências funestas, elevando o grau de vulnerabilidade do consumidor, vindo, ainda, a retirar a dignidade daquele indivíduo consumidor violando seus direitos mais fundamentais.

Em todo este contexto, importante destacar o acesso ao crédito fácil como um dos fatores do superendividamento, caracterizado pelo consumo exacerbado de tentar satisfazer os desejos da sociedade de consumo, ou até mesmo como válvula de escape para a tentativa de sanar os problemas de endividamento, mas ainda assim, representa risco de insolvência do indivíduo.

Fossa (2012, p. 6) manifesta que "constantemente aumenta o número de pessoas que assumem dívidas excessivas não podendo quitá-las, por não terem arrecadado mais do que gastam, assim pessoas acabam entrando em estado de inadimplência, consequentemente, superendividando-se".

Espolador e El Kadri (2012, p. 12) apontam o crédito fácil como um problema do indivíduo e da sociedade. Explicam que "o consumo, por meio do crédito democratizado, massificado, demonstra-se um grande problema do indivíduo e da sociedade, na medida em que de facilitador, pode tornar-se o pior pesadelo da sociedade de consumo: o superendividamento do consumidor".

Pode-se dizer que na sociedade de consumo os valores se encontram invertidos. Isto posto, o consumismo dita que o ter é mais importante que o ser, podendo-se dizer que a questão do superendividamento é 
uma valoração social do consumo. Nota-se que o indivíduo consome mais que o seu orçamento pode suportar.

Destarte, sabe-se que o crédito possui como função social o de promoção do desenvolvimento econômico e o equilíbrio dos Estados, e deve servir aos interesses da coletividade, conforme preconiza o art. 192 da Constituição Federal, o que de fato, não acontece diante a falta de regulamentação da concessão de crédito e, como consequência, desrespeita a dignidade dos indivíduos quanto consumidores.

\section{A FACILIDADE DO CRÉdiTO ATRAVÉS DO MARKETING E DO COMÉRCIO ELETRÔNICO}

É certo que em uma sociedade pautada pelo consumo exacerbado surjam novos desejos e necessidades para os indivíduos consumidores, os quais eram taxados como impossíveis para a maior parte da população de renda mínima, mas, que, tornaram-se acessíveis graças à facilitação do crédito.

Observa-se através da história da civilização ocidental moderna que, a partir do século XIX e XX, houve uma aceleração do desenvolvimento do crédito, podendo-se perceber a sua democratização em razão, principalmente, da consagração da venda parcelada (PELLEGRINO, 2014, p. 138).

Marques (2010, p. 54, apud PELLEGRINO, 2014, p. 142) esclarece que o "crédito é um tempo que a pessoa adquire por meio de contratos diversos (cartões de crédito, crédito retroativo, cheque especial, carnês assegurados por nota promissória, etc.) para pagar as suas dívidas".

O crédito poder ser definido como o ato pelo qual o indivíduo - fornecedor do crédito - que é detentor do capital e de forte poder econômico, concede fundos ao indivíduo consumidor - sem capital, sem recursos financeiros - a título oneroso, ou seja, promovendo uma troca de bens.

A facilitação do crédito aos indivíduos torna-se um fator de inclusão dos mesmos na sociedade de consumo e não apenas como uma forma de se elevar o padrão de vida. Assim, poder-se-á afirmar que a concessão do crédito é sinônimo de status social.

Conforme visto, devido à inversão dos valores entre ser e ter, hoje, para que seja possível a inclusão daquele indivíduo consumidor na sociedade de consumo, é necessário que ele tenha recursos financeiros, o que torna o crédito um elemento essencial para a aquisição de produtos e serviços.

Ainda, pode-se dizer que o crédito possui três acepções, como a moral, a jurídica e a econômica, assim:

O crédito tem três acepções: moral, jurídica e econômica. A moral se relaciona à honra, à dignidade da pessoa e à sua reputação ilibada, que reflete na credibilidade da pessoa perante a sociedade de consumo. A jurídica que se traduz na adimplência das prestações, direito do credor a ser cumprido pelo devedor; e a econômica que se traduz na negociação de um contrato de entrega de bem ou serviço imediato por uma obrigação futura. (REBOUÇAS, 2002, p. 62).

Nota-se que o crédito está diretamente ligado à nova sociedade de consumo e, por conseguinte, ao 
fenômeno do superendividamento, de maneira que a facilitação do acesso ao crédito tornar-se uma das principais causas do superendividamento.

Dentre as modalidades de acesso ao crédito, importante destacar as proporcionadas pelos Bancos instituições de crédito, que possibilitam diversas operações como: operação de crédito, recepção de depósitos, cheques, comercialização de contratos, seguros, emissão de pagamento, carta de créditos, cartões de créditos, entre outras.

Destas, em especial, necessário se faz elucidar o cartão de crédito, o qual é considerado como meio de pagamento, para uso eletrônico ou não, emitido por uma instituição de crédito e que visa possibilitar ao indivíduo consumidor titular do cartão a utilização de crédito a ser outorgado pela administradora do cartão.

O cartão de crédito pode, então, ser utilizado como meio de pagamento pelos "usuários por conveniência", permitindo a coordenação de rendimento e consumo, aplainando a volatilidade no rendimento e nas despesas e reduzindo os valores que os indivíduos precisam manter em conta corrente. Através dele também pode o consumidor recorrer ao flexível crédito propriamente dito, quando opta pelo pagamento parcial das faturas (são os tomadores de empréstimos), sem um termo fixo ou programação de reembolso, além do pagamento mínimo. (PELLEGRINO, 2014, p. 151).

Dá-se maior ênfase nessa modalidade por tratar-se de uma das principais formas de acesso ao crédito e decorrente à facilidade que o cartão de crédito apresenta aos consumidores para aquisição de bens de qualquer lugar do mundo, tanto via estabelecimento comercial como pelo comércio eletrônico.

O consumidor é seduzido diariamente para essa felicidade instantânea através da agressividade da publicidade, favorecendo ainda mais o ambiente para que o consumidor venha a tornar-se insolvente diante suas obrigações.

Com base em todas as informações apresentadas, percebe-se que o fornecedor de produtos e serviços, utiliza-se de estratégias publicitárias e de marketingpara associar a aquisição daquele bem de consumo a satisfação de desejos criados nos consumidores, na finalidade de estimular o consumismo.

Ainda, tem-se que com o surgimento da internet e a crescente utilização de tecnologias, o que permite um acesso mais amplo pelos indivíduos ao comércio eletrônico, produzindo transformações na sociedade, potencializando a publicidade para a possibilidade de acesso ao crédito.

Nesse sentido, o meio virtual vem sendo a forma utilizada para a realização de contratações, assim:

Trata-se de negócios contratuais que não são paritários e que não são firmados presencialmente com assinatura de um documento físico pelos contratantes, mas sim, em condição de simples adesão, à distância, mediante utilização de meios eletrônicos como email, tablets ou celulares, praticados on line ou de alguma forma por meio de comunicação em massa. (PRUX, 2016, p. 51)

Com o surgimento da internet, tem-se o surgimento natural do comércio eletrônico que consiste em uma modalidade de compra a distância, permitindo ao consumidor a possibilidade de realizar um negócio através do computador, tablets, smartphone e afins. 
O comércio eletrônico como consequência natural do sucesso da Internet, apresenta-se igualmente como um fenômeno irreversível. Sendo assim, o comércio eletrônico nada mais é do que uma modalidade de compra, de bens e/ou serviços, à distância, utilizando-se de equipamentos eletrônicos de tratamento e armazenamento de dados, nos quais são transmitidas e recebidas informações a respeito do que se está comprando. O mundo digital trouxe consigo a possibilidade da realização de diversos negócios através do computador. (CATANA; DE SOUZA, 2009, p. 1162).

Ademais, com essa nova modalidade de contratação, tem-se o surgimento dos chamados documentos eletrônicos, os quais podem ser definidos como aqueles provindos da celebração de um negócio jurídico por meio digital, principalmente, pela Internet.

Não obstante, com o surgimento da internet, principalmente, com o comércio eletrônico o consumidor viu a possibilidade de realizar contrato de consumo com fornecedores de qualquer lugar do mundo, acabando com a noção de territorialidade.

Importante destacar as formas com que se dão as práticas de marketing como meio de atrair o consumidor, assim:

Ainda, no que se refere ao comércio eletrônico é possível verificar determinadas formas de marketing como, o marketing viral que se dá através da promoção de determinado produto ou serviço que se auto promove propagando-se pela rede como um vírus; o marketing de permissão que pode ser definido como aquele em que o consumidor permite o recebimento de mensagens de ofertas por e-mail; o marketing spam que consistem no recebimento de propagandas não solicitadas (BRASIL. Ministério da Ciência e Tecnologia, 2001).

Dentre as formas de marketing, destaca-se o spam, meio pelo qual o indivíduo consumidor recebe diariamente ofertas de diversos fornecedores, sem que tenha ocorrido a sua permissão, exemplo muito comum, as ofertas recebidas via e-mail que, em sua maioria, são dirigidas automaticamente para a lixeira.

É importante destacar que no atual cenário da sociedade de consumo a publicidade possui grande relevância, podendo ser considerada como um dos propulsores para o incentivo ao acesso ao crédito.

Ainda quanto a publicidade por meio do comércio eletrônico, temos que:

Há um direcionamento para apresentar ofertas e concretizar contratações, de forma indiferente às possibilidades de distorções ou omissões do fornecedor quanto à bem informar ou mesmo com referências às dificuldades inerentes a apresentação do produto quando há utilização tão-somente texto, imagem e som, sem haver condição para o tato, o olfato, o paladar e, principalmente, o contato direto com o objeto a ser adquirido. (PRUX, 2016, p. 51)

Nessa toada, importante trazer as palavras de Nancy Andrighi, Ministra do Supremo Tribunal de Justiça, sobre o aumento progressivo das negociações através do comércio eletrônico, assim:

Na última década, o aumento nas vendas online foi de $3.000 \%$ e, ano após ano, o crescimento no e-commerce é maior do que em lojas físicas. Mesmo com a grave crise na economia brasileira, no primeiro semestre de 2015 o comércio eletrônico cresceu $16 \%$ em relação ao mesmo período de 2014. Ao passo que o comércio eletrônico no Brasil registrou crescimento de $26 \%$ nas vendas de 2014 em relação a 2013, o varejo físico cresceu apenas 2,2\% no mesmo período. (ANDRIGHI, 2015, p. 646)

Destarte, aponta ser muito comum as instituições financeiras utilizarem-se do marketing através dos 
meios de comunicação em massa, principalmente o comércio eletrônico para seduzir o consumidor a facilidade de acesso ao crédito.

Poder-se-á concluir que a utilização das práticas de marketing através do próprio comércio eletrônico para a captação de consumidores para o acesso ao crédito democratizado é prática corriqueira na sociedade de consumo.

\section{O DESAFIO DA DEFESA DO CONSUMIDOR EM TEMPOS DE GLOBALIZAÇÃO EM FACE AO_SUPERENDIVIDAMENTO}

O fenômeno da globalização e os avanços tecnológicos fomentam a distribuição de bens e serviços e constituem uma ferramenta para o desenvolvimento econômico; contudo, a massificação de ofertas de produtos e serviços, aliadas às pseudo-promoções, bem como a facilidade de crédito, acarretam desequilíbrios nas relações de consumo, fazendo com que o fornecedor passe a ocupar posição superior na relação consumerista, acentuando ainda mais a vulnerabilidade do consumidor.

O CDC é considerado um marco no ordenamento jurídico brasileiro ao estabelecer diretrizes para harmonizar e equilibrar as relações de consumo.

No entanto, é preciso destacar que o CDC foi implementado num período em que não existiam as facilidades de acesso a produtos e serviços, a facilidade de acesso ao crédito, assim como o comércio eletrônico.

Sob o ponto de vista dos meios para a empresa promover a oferta do produto, esta se insere no contexto do comércio eletrônico quando atua com o emprego de meios eletrônicos, em geral, ou a Internet, em particular (DAVARA RODRÍGUEZ, 2007), assim, o legislador infraconstitucional não poderia prever as transformações tecnológicas e mercadológicas que surgiram a partir de então, nomeadamente em face de a Internet ter sido impulsionada no Brasil a partir da segunda metade da década de 1990.

A discussão sobre o superendividamento é de caráter social ao tratar da defesa do consumidor como um fator de inclusão social e, também, de caráter jurídico, ao analisar a lacuna no ordenamento jurídico brasileiro enquanto um fator agravante da situação de vulnerabilidade do consumidor, fatores que colocam em risco a sua dignidade.

O projeto de lei no 283/2012, em trâmite no Senado Federal e que visa reformar o CDC, tem por finalidade a inclusão de normas de caráter principiológicas referentes à concessão de crédito e meios de prevenir o superendividamento, ao tratar do instituto quanto à oferta, contratação, prevenção e conciliação.

O projeto de lei visa acrescentar aos princípios da Política Nacional das Relações de Consumo, art. 4, questões fundamentais como o fomento a ações que visam à educação financeira dos consumidores e a prevenção e tratamento do superendividamento como forma de evitar a exclusão social do consumidor, incisos IX e X. 
Ainda, apresenta novos instrumentos a serem utilizados pelo Poder Público para a execução da Política Nacional da Relação de Consumo, art. 5º, prevendo a instituição de mecanismos de prevenção e tratamento extrajudicial e judicial do superendividamento e proteção do consumidor e a instituição de núcleos de conciliação e mediação de conflitos originados do superendividamento, por meio do acréscimo dos incisos VI e VII.

Não obstante, o rol de direitos do consumidor será ampliado devendo ser elencado no art. $6^{\circ}$ os direitos como: a garantia prática de crédito responsável, de educação financeira, de prevenção e tratamento das situações de superendividamento, preservando-se o mínimo existencial do devedor, por meio de revisão e repactuação das dívidas, incisos XI e XII.

Para a preservação do mínimo existencial, será compreendido determinada quantia mínima que será destinada a manutenção de despesas mensais razoáveis para a sobrevivência, como as despesas de água, luz, alimentação, moradia, saúde e educação.

O Projeto de Lei visa, ainda, a criação do da Seção IV no Capítulo IV, intitulada Da Prevenção e do Tratamento ao Superendividamento, na finalidade de prevenir esse fenômeno com a promoção da educação financeira e acesso ao crédito de forma responsável, fundado sempre no mínimo existencial, boa-fé, função social do crédito e do princípio da dignidade da pessoa humana.

É certo que através dessas medidas o Estado deverá vir a intervir nas relações de consumo no objetivo de assegurar a proteção fundamental do consumidor e coibir possíveis práticas abusivas no mercado de consumo, corroborando para o uso do crédito consciente.

Diante todo o contexto exposto, é evidente que o consumidor possui como uma de suas características o fator da vulnerabilidade, que o caracteriza como a parte mais fraca da relação de consumo. O superendividamento apresenta-se como um vetor da vulnerabilidade agravada.

A atualização do Código de Defesa do Consumidor é urgente, necessária e representa a aplicação do princípio do estudo das modificações do mercado de consumo, de modo que o fator do superendividamento deve ser regulamentado para que decorra a devida proteção ao consumidor e efetivação de um mínimo digno para a sua própria existência como ser humano.

\section{CONSIDERAÇÕES FINAIS}

O desenvolvimento do fenômeno da globalização origina a nova sociedade de consumo e cria novas expectativas, a qual a standartização de produtos e serviços seduzem e despertam novos desejos aos consumidores. A sociedade passa a ser marcada pelo consumismo, de maneira que o indivíduo busca a sua satisfação pessoal na aquisição de produtos e serviços.

A Constituição Federal de 1988 inseriu a Proteção do Consumidor como um direito fundamental do 
ordenamento jurídico brasileiro e trouxe o consumidor como um agente econômico e social, fazendo-se necessário a intervenção estatal para a efetiva garantia desse direito.

Ademais, em 1990 foi introduzido em nosso ordenamento, o Código de Defesa do Consumidor que visa regulamentar as relações de consumo através de diretrizes nacionais para a proteção do consumidor a fim de promover a harmonização e o equilíbrio nessa relação de desiguais.

Todavia, evidente que a norma consumerista por si só não é suficiente para lidar com o fenômeno do superendividamento, o qual não possui normas específicas.

O superendividamento surge como algo novo na ordem jurídica e faz despertar a atenção da comunidade jurídica e do poder público diante seus reflexos na economia, na vida social do consumidor endividado e à necessidade de prevenção e regulamentação para esse fenômeno, fazendo-se necessária a criação de políticas públicas para o real enfrentamento desse problema econômico, social e jurídico.

Não obstante, o superendividamento é um problema social ao ponto em que coloca em risco a dignidade do indivíduo, afetando o mínimo necessário para a sua sobrevivência, podendo vir a acarretar uma situação de exclusão social.

Ainda, torna-se um problema da ordem econômica, na medida em que, o crédito fácil e desmedido apresenta-se como uma das principais causas do superendividamento, e, também, decorrente do aumento desta situação, necessário se faz uma regulamentação normativa, apresentando-se como um problema jurídico.

Variados são os motivos que levam o consumidor ao superendividamento, desde a vontade de consumir para alcançar um determinado status social ou a satisfazer suas necessidades de acordo com suas prioridades, ou até mesmo por decorrência de alguma eventualidade, como o desemprego.

Independentemente das causas que dão origem ao superendividamento, fato é que a cada dia mais os consumidores são expostos a inúmeras publicidades e ofertas que comprometem todo o seu orçamento, colocando em risco o mínimo para a sua subsistência.

O princípio da dignidade da pessoa humana é essencial à democracia, colocando o bem estar do ser humano como função primordial do Estado Democrático de Direito, sendo assim, um valor absoluto, vedando tudo que possa afetar a qualidade de vida do indivíduo, assegurando a integridade das pessoas só por sua existência.

A sociedade de consumo decorre paralelamente do fenômeno da globalização e do capitalismo e produz como consequência a questão do superendividamento. A falta de regulamentação normativa específica sobre o tema apresenta uma norma consumerista ultrapassada para atual realidade do mercado de consumo.

É urgente a necessidade de atualização do Código de Defesa do Consumidor, pois a falta de regulamentação e prevenção para a questão do superendividamento viola diretamente o direito fundamental de 
proteção ao consumidor e, nesse contexto, nega ao indivíduo uma expectativa de melhor bem estar de vida, colocando-o em situação de risco social e, ainda, deixando-o comprometer o mínimo para uma vida digna.

Assim, conclui-se, que a falta de regulamentação para o fenômeno do superendividamento é um desrespeito ao fundamento da dignidade da pessoa humana que sustenta o valor supremo de um Estado Democrático de Direito.

\title{
THE FUNDAMENTAL RIGHT OF PROTECTION TO CONSUMER IN TIMES OF GLOBALIZATION AND THE PHENOMENON OF INDEBTEDNESS
}

\begin{abstract}
This research aims to analyze and verify the phenomenon of globalization as a way to facilitate communication between nations and the purpose of promoting business practices, enhancing their development corroborated to a new social context of production, which brings out to a new company called consumer society. Through literature and legislative review, it highlights the evolution of consumer relations and it appears that, although consumer protection has been positively valued the Brazilian legal system by the Constitution/ 88 as a fundamental right, regulated and has been enacted the Consumer Protection Code in 1990, the indebtedness of the phenomenon as a consequence of globalization remains unregulated. The survey stake the importance of consumption in the inclusion or exclusion of citizens in today's consumer society and its reflection on the principle of dignity, as necessary, also check the social and legal consequences of these phenomena in society and examine the causes of over-indebtedness and the challenge faced to be effective consumer protection at the gap of consumerist standard, although today transact in the Senate, a bill that aims to control credit and prevent overindebtedness.
\end{abstract}

Keywords: Consumption; Fundamental right; Globalization; Consumer Protection; Over indebtedness.

\section{REFERÊNCIAS}

ANDRIGHI, Fátima Nancy. Perspectivas para o aprimoramento do direito do consumidor. In: MIRAGEM, Bruno; MARQUES, Claudia Lima; FLÁVIO DE OLIVEIRA, Amanda (Org.). 25 anos do código de defesa do consumidor: trajetória e perspectivas. São Paulo: Revista dos Tribunais, 2015. p. 639-654.

Senado Federal. Constituição Federal. Disponível em:

http://www.planalto.gov.br/ccivil_03/Constituicao.htm. Acesso em: 25 fev. 2016.

Senado Federal. Projeto de Lei do Senado Federal no 283/2012. Disponível em:http://www.senado.gov.br/atividade/materia/Consulta=ano2014. Acesso_em: 07 mar. 2016.

Senado Federal. Relatório-Geral Comissão de Juristas de Atualização do Código de Defesa do Consumidor. Disponível em: http://www.senado.gov.br/codconsumidor/pdf/relatorio_final.pdf. Acesso em: 10 fev. 2016.

Ministério da Ciência e Tecnologia. Secretaria de Política de Informática. Internet comercial. conceitos estatísticas e aspectos legais. Brasília, DF, 2001. Disponível em: http://www.mct.gov.br/upd_blob/0008/8707.pdf_Acesso em: 05 mai. 2016. 
BARCHET, Gustavo; MOTTA, Sylvio. Curso de Direto Constitucional. 2a ed.. Rio de Janeiro: Editora; Elsevier, 2009. $1096 \mathrm{p}$.

BRANCO, Paulo Gustavo Gonet; MENDES, Gilmar Ferreira. Curso de Direito Constitucional. 9a ed. São Paulo: Saraiva, 2014. 1504 p.

BOLADE, Geisianne Aparecida. O Superendividamento do Consumidor como um Problema Jurídico-Social. ANIMA: Revista Eletrônica do Curso de Direito das Faculdades OPET. Curitiba PR-Brasil. Ano III, n. 8, p. 180$209,2012$.

BOLZAN, Fabrício; LENZA, Pedro. Direito do consumidor esquematizado. São Paulo: Saraiva, 2015. 735 p.

CANOTILHO, José Joaquim Gomes. Direito Constitucional e Teoria da Constituição. 7a ed. Coimbra: Almedina, 2000. $1522 \mathrm{p}$.

CARVALHO, Sonia Aparecida. Sustentabilidade, Globalização, Tecnologia e Consumo: Estratégias de Governança Global. Revista Eletrônica Direito e Política, Itajaí, v.10, n.1, p. 1-23, 2015. Disponível em: www.univali.br/direitoepolitica. Acesso em: 08 fev. 2016.

CATANA, Luciana Laura Tereza Oliveira; DE SOUZA, Vinicius Roberto Prioli. Direitos Reais no Consumo Virtual. Etic-Encontro de Iniciação Científica-ISSN 21-76-8498, v. 2, n. 2, 2009.

DAVARA RODRÍGUEZ, Miguel Ángel. Manual de Derecho Informático. 9 ed. Navarra: Arazandi, 2007.

ESPOLADOR, Rita de Cássia Resquetti Tarifa, EL KADRI, Nádia Mahmoud Safade. Globalização, consumo e superendividamento. In.: Conselho Nacional de Pesquisa e Pós-Graduação em Direito, 21., Niterói/RJ, 2012. Anais... Conpedi: Florianópolis, p. 2722-2746, 2012. Disponível em: http://www.publicadireito.com.br/artigos/cod=07a96bl. Acesso em: 29 mar. 2016.

FERNANDES, Daviton Gurgel Guerra. A questão do superendividamento no ordenamento jurídico brasileiro pós constituição federal de 1988 e as reformas do CDC. Revista Pesquisas Jurídicas, v. 4, n. 3, p. 55-72, 2015.

FOSSÁ, Carolina Olivaes. O Superendividamento de Acordo com o Projeto de Lei de Reforma do Código de Defesa do Consumidor. 2012. 30 p. Trabalho de Conclusão de Curso (Bacharel em Ciências Jurídicas e Sociais), Pontífica Universidade Católica. Rio Grande do Sul: Porto Alegre, 2012. Disponível em: http://www.pucrs.br/direito/carolina_fossa.pdf. Acesso em: 11 jan. 2016.

GIDDENS, Anthony. As consequências da modernidade. Raul Fiker (trad.). São Paulo: Editora Unesp, 1991.

LIMA, Cyntia Costa; AYALA, Cecílio Arnaldo Rivas. O Problema da Sociedade de Consumo na Sociedade de Risco e a Alternativa pela via da Sustentabilidade. In.: Universitas e Direito, 1., Curitiba/PR, 2012. Anais... PUCPR: Curitiba, p. 169-189, 2012. Disponível em: http://www.pucpr.br//index.php/universitas=anais. Acesso em: 08 fev. 2016.

MARQUES, Claudia Lima. Consumo como igualdade e inclusão social: a necessidade e uma lei especial para prevenir e tratar o "superendividamento" dos consumidores pessoas físicas. Revista Jurídica da Presidência, Brasília, v. 13 n. 101, p. 405-424, 2010. Disponível em: https://revistajuridica.presidencia.gov.br/article/119. Acesso em: 05 mar. 2016. 
PELLEGRINO, Fabiana Andréa de Almeida Oliveira. A tutela em face do superendividamento na perspectiva de uma hermenêutica contemporânea das relações de consumo. 2014.272 p. Dissertação - (Mestrado em Direito), Universidade Federal da Bahia: Salvador. 2014. Disponível em: https://repositorio.ufba.br/ri/handle/ri/16610. Acesso em: 10 mai. 2016.

PRUX, Oscar Ivan. 25 anos do código de proteção e defesa do consumidor, sua história e as novas perspectivas para o século XXI. In.: MIRAGEM, Bruno; MARQUES, Claudia Lima; FLÁVIO DE OLIVEIRA, Amanda (Org.). 25 anos do código de defesa do consumidor: trajetória e perspectivas. São Paulo: Revistas do Tribunais, 2015.p. 33-80.

REBOUÇAS, Idma Maria. Significado e importância do microssistema jurídico consumerista: a questão do superendividamento: perspectiva e soluções. 2002. 188 p. Dissertação - (Mestrado em Direito), Universidade Federal de Pernambuco - UFPE: Recife. 2002. Disponível em: http://www.repositorio.ufpe.br/bitstream/handle/123456789/4405/arquivo5573_1.pdf?sequence=1\&isAllow ed $=y$. Acesso em: 10 mai. 2016.

RETONDAR, Anderson Moebus. A (re)construção do indivíduo: a sociedade de consumo como "contexto social" de produção de subjetividades. Sociedade e Estado, Brasília, v. 23, n. 1, p. 137-160, 2008. Disponível em: http://www.scielo.br/scielo1\&hl=br. Acesso em: 18 fev. 2016.

SILVEIRA NETO, Antônio. A Ordem Econômica Globalizada e as Relações de Consumo: aspectos relativos à proteção do consumidor. Revista Prima Facie - Direito, História e Política, Campina Grande, v.1, n,1. p. 1-11, 2002. Disponível em: http://periodicos.ufpb.br/index.php/search/=title. Acesso em: 01 mar. 2016.

Trabalho enviado em 26 de setembro de 2016.

Aceito em 05 de março de 2017. 